\title{
Modeling and simulation of high-pressure industrial autoclave polyethylene reactor
}

\author{
E. Caliani ${ }^{1}$, M. Cavalcanti ${ }^{2}$, L. M. F. Lona ${ }^{1}$, F. A. N. Fernandes ${ }^{3 *}$ \\ ${ }^{1}$ Universidade Estadual de Campinas, Faculdade de Engenharia Química, Campinas - SP, Brazil \\ ${ }^{2}$ Politeno Indústria e Comércio S/A, Camaçari - BA, Brazil \\ ${ }^{3}$ Universidade Federal do Ceará, Departamento de Engenharia Química, Campus do Pici, Bloco 709, 60455-760 Fortaleza \\ $-\mathrm{CE}$, Brazil
}

Received 23 October 2007; accepted in revised form 12 November 2007

\begin{abstract}
High-pressure technology for polyethylene production has been widely used by industries around the world. A good model for the reactor fluid dynamics is essential to set the operating conditions of an autoclave reactor. The high-pressure autoclave reactor model developed in this work was based on a non-isothermal dynamic model, where PID control equations are used to maintain the operation at the unstable steady state. The kinetic mechanism to describe the polymerization rate and molecular weight averages are presented. The model is capable of computing temperature, concentration gradients and polymer characteristics. The model was validated for an existing industrial reactor and data for production of homopolymer polyethylene and has represented well the behavior of the autoclave reactor used in ethylene homopolymerization.
\end{abstract}

Keywords: modeling and simulation, polyethylene, LPDE, polymerization, autoclave reactor

\section{Introduction}

Low density polyethylene is produced by highpressure processes either in autoclave vessel reactors or in tubular reactors. The process requires a highly purified ethylene feed and the operating pressure ranges from 1000 to $3000 \mathrm{~atm}$. This work has developed a mathematical model based on the mixing model for the production of low density polyethylene in an industrial high-pressure autoclave vessel reactor and has compared the results with industrial data.

Several modeling techniques have been used to model this type of reactor [1-6] and some authors have shown that the mixing model is best fitted to this process. Although the mixing model is already known, few studies [1,7-10] have reported and compared the results obtained from the mixing model with actual industrial data. Furthermore, the autoclave vessel reactor has a complex controlling system where the temperature is controlled by the feed flow rate of initiator into the reactor and until now no study has published values for the PID controller parameters.

\section{Autoclave vessel reactor}

The autoclave vessel reactor is an autoclave with high length to diameter ratio, divided into several compartments. The reaction requires high power input per unit of volume to maintain good mixing conditions in each compartment. Because of the thickness of the wall, low surface area, and high heat load, the reactor can be considered essentially adiabatic. Polymerization temperature ranges from

*Corresponding author, e-mail: fabiano@ufc.br

(C) BME-PT and GTE 


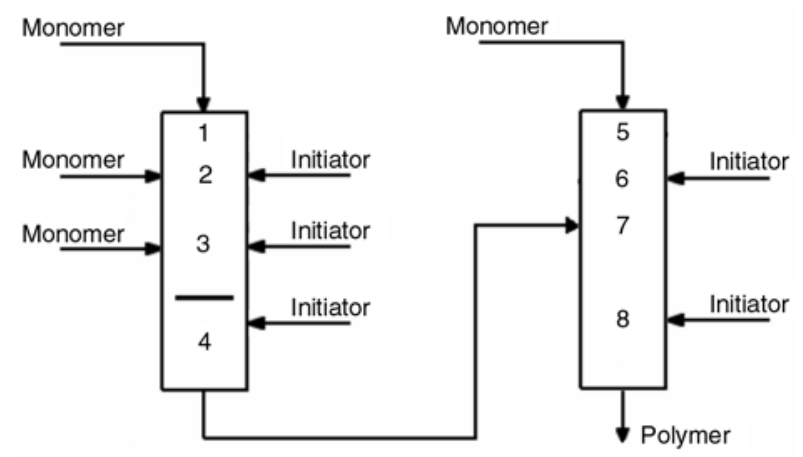

Figure 1. Industrial high-pressure vessel reactor

150 to $300^{\circ} \mathrm{C}$ and is set depending on the desired LDPE grade. Temperatures above $300^{\circ} \mathrm{C}$ should be avoided because of possible polyethylene decomposition. Fresh ethylene is fed to some compartments together with a radical source, usually an azocompound or peroxide, which decomposes and generates free radicals starting the polymerization reaction [3].

The reactor system modeled in this work consists of a series of two autoclave vessel reactors connected in series as shown in Figure 1. Fresh ethylene is fed into sections $1,2,3$ and 5 of the reactors and the product from the first reactor is fed into section 7 of the second reactor. Mixing, in both reactors, is provided by a shaft running down the center of the reactor with several impeller blades. In the first reactor a baffle is placed near the bottom of the reactor to reduce backmixing of the mixture.

Heat transfer through the walls is limited and cooling is provided by the inflow of cold monomer. Temperature is controlled regulating the inflow of initiator to the reactor. Initiator is fed into sections 2, 3, 4, 6 and 8. Sections 1 and 5 (first section of each reactor) have low reaction rates and have the primary function of cooling the agitator motor.

\section{Mixing model}

The mixing pattern in an autoclave type reactor tends to be of a recirculating nature. The effect of mixing on reactor performance is very important, especially because an imperfectly mixed vessel requires more initiator per unit of polymer produced than does a more perfectly mixed reactor under the same conditions [2]. The initiator tends to decompose near the feed points and not in the bulk of the reactor, thus not promoting as much polymerization as if the initiator were uniformly distributed throughout the reaction mixture. The temperature gradient down the reactor also suggests imperfect mixing [1].

The mixing pattern in the high-pressure reactor makes it behave more like a continuous stirred tank reactor (CSTR) rather than a tubular reactor. To account for imperfect mixing in the reactor, the autoclave reactor can be subdivided into several sections which can be represented by a series of small reactors consisting of a CSTR segment followed by a plug-flow segment that accounts for the temperature gradient down the reactor. Each plugflow segment can be modeled as a series of small volume CSTRs avoiding to solve partial differential equations. The back mixing promoted by the impeller blades is considered, allowing each main CSTR segment of the reactor to recycle part of its volume back to the previous CSTR main segment (Figure 2).

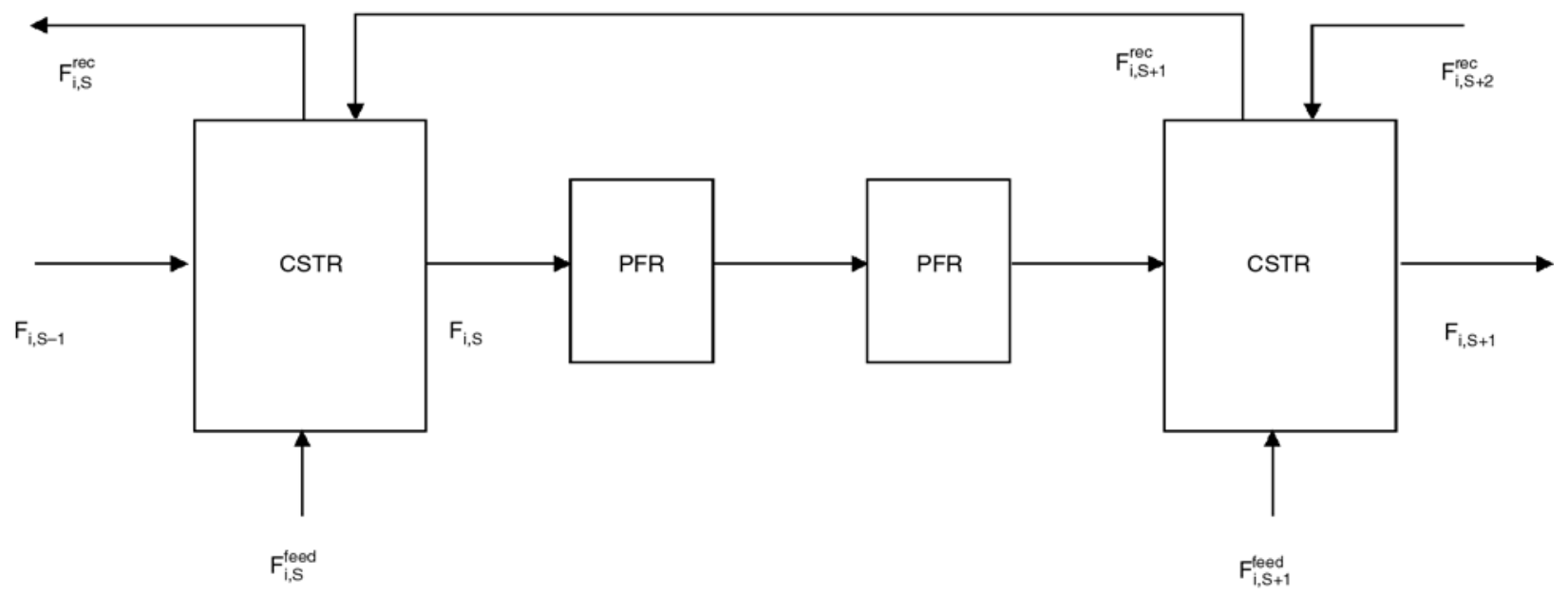

Figure 2. Mixing model structure and flow rates between two sections of the reactor 
The mathematical model developed herein includes temperature controller equations to maintain the operation point at a desired steady state. The controller equations are needed because the industrial reactor normally operates at an unstable steady state in which the operation can either cause the temperature to rise or to cool down the reactor until no polymerization occurs.

Based on the flow rates shown in Figure 2, the mass balance for a species in a volume segment of the reactor is given by Equation (1):

$$
\begin{aligned}
& \frac{\mathrm{d} N_{i, S}}{\mathrm{~d} t}= F_{i, S}^{\text {feed }}+F_{i, S-1}+F_{i, R}^{r e c}-F_{i, S}-F_{i, S}^{r e c}+r_{i, S} \cdot V_{S} \\
&(i, S \geq 1)
\end{aligned}
$$

where, $F_{i, S}$ is the molar flow rate of the component $i$ in the section $S[\mathrm{~mol} / \mathrm{s}] ; N_{i, S}$ is the number of mols of the component $i$ in the section $S$ [mol]; $r_{i, S}$ is the reaction rate of the component $i$ in the section $S$ $[\mathrm{mol} / \mathrm{s} \cdot \mathrm{l}] ; t$ is the time [s]; $V_{S}$ is the volume of the section $S$ [1]; and the superscript feed refers to the feed stream and rec refers to the recycle stream.

The plug-flow segments (PFR) do not have feed streams nor recycle streams going to other segments, and for these segments Equation (1) can be simplified to Equation (2):

$$
\frac{\mathrm{d} N_{i, S}}{\mathrm{~d} t}=F_{i, S-1}-F_{i, S}+r_{i, S} \cdot V_{S} \quad(i, S \geq 1)
$$

To evaluate the effect of the macromixing parameters on the reactor fluid dynamics, two main parameters were defined: volume fraction of the CSTR segment to the total volume of the section $(\theta)$ and recycle ratio ( $\beta$ ), as shown in Equations (3) and (4):

$$
\theta=\frac{V_{S, C S T R}}{V_{S, T O T A L}}
$$

$\beta=\frac{Q_{S}^{r e c}}{Q_{S}+Q_{S}^{r e c}} \quad(S \geq 1)$

where, $Q_{S}$ is the total volumetric flow rate of the section $S[1 / \mathrm{s}] ; Q_{S}^{r e c}$ is the volumetric flow rate of the recycle stream exiting the section $S[1 / \mathrm{s}] ; V_{S, C S T R}$ is the volume of the CSTR segment of the section $S$ [1]); $V_{S, T O T A L}$ is the total volume of section $S$ [1]; $\theta$ is the recycle ratio; and $\theta$ is the volume fraction of the CSTR segment to the total volume of section $S$.
These parameters should be estimated for each reactor and for each section in the reactor. High $\theta$ values denote that the section resembles an ideal CSTR, while high $\beta$ values denote good axial mixing among contiguous sections.

The energy balance of the reactor requires accounting for the inflows, outflows, recycles and reaction in each segment (Equation (5)). The reactor is assumed to be adiabatic and cooling is supplied by cold monomer feed. Heat generation is considered to come from the propagation reaction only.

$$
\begin{aligned}
\left(\rho_{S} \cdot C p_{S} \cdot V_{S}\right) \frac{\mathrm{d} T_{S}}{\mathrm{~d} t}= & \rho_{S}^{\text {feed }} \cdot Q_{S}^{\text {feed }} \cdot C p_{S}^{\text {feed }} \cdot\left(T_{S}^{\text {feed }}-T_{r e f}\right)+ \\
& \rho_{S-1} \cdot Q_{S-1} \cdot C p_{S-1} \cdot\left(T_{S-1}-T_{r e f}\right)+ \\
& \rho_{R}^{r e c} \cdot Q_{R}^{r e c} \cdot C p_{R}^{r e c} \cdot\left(T_{R}^{r e c}-T_{r e f}\right)- \\
& \rho_{S} \cdot Q_{S} \cdot C p_{S} \cdot\left(T_{S}-T_{r e f}\right)- \\
& \rho_{S} \cdot Q_{S}^{r e c} \cdot C p_{S} \cdot\left(T_{S}-T_{r e f}\right)-\Delta H \cdot r_{S} \cdot V_{S}
\end{aligned}
$$

where, $C p_{S}$ is the heat capacity of the mixture in section $S[\mathrm{~J} / \mathrm{g} \cdot \mathrm{K}] ; T_{S}$ is the temperature of section $S[\mathrm{~K}] ; T_{\text {ref }}$ is the reference temperature $[\mathrm{K}] ; \rho_{S}$ is the density of the mixture in section $S$ [g/l]; $\Delta H$ is the heat of reaction $[\mathrm{J} / \mathrm{mol}]$.

Temperature is controlled by manipulating the flow rate of the initiator feed stream based on the actual temperature of some measured segments and on the set-point temperature. The controller applied to the reactor modeled herein was a proportional-integralderivative type (PID controller - Equation (6)) and 5 controllers were used to control the initiator feed into sections 2, 3, 4, 6 and 8, as in the industrial reactor.

$$
\begin{aligned}
& \Delta F_{I}= \\
& K_{c} \cdot\left[\left(E_{n}-E_{n-1}\right)+\frac{\Delta t}{\tau_{I}} \cdot E_{n}+\frac{\tau_{D}}{\Delta t} \cdot\left(E_{n}-2 \cdot E_{n-1}+E_{n-2}\right)\right]
\end{aligned}
$$

where, $F_{I}$ is the molar flow rate of initiator in the initiator feed stream $[\mathrm{mol} / \mathrm{s}] ; K_{c}$ is the proportional gain $[\mathrm{mol} / \mathrm{s} \cdot \mathrm{K}] ; E$ is the error between the actual temperature and the set-point temperature $[\mathrm{K}]$; $\tau_{I}$ is the integral gain [s]; and $\tau_{D}$ is the differential gain $[\mathrm{s}]$. 
Ethylene free radical polymerization mechanism and kinetics was outlined by Zabisky et al. [11] and Chan et al. [1] for a two phase kinetic mechanism where a monomer and a polymer rich phase exist in the reaction mixture. Herein, a homopolymer presenting only one phase in the reactor (monomer rich phase) was assumed and the momentum equations to account for the molecular weight of the polymer were adapted from Zabisky et al. [11] for a one phase kinetic mechanism.

The kinetic mechanism considered the initiation of radical by thermal decomposition of the initiator, chain propagation, termination by combination and disproportionation, transfer to monomer and to polymer and reaction with terminal double bound. The moments for live and dead polymers are given by Equations (7) to (12). The fraction of dead polymers with terminal double bond was calculated dividing the reaction rates of the reactions that produce dead polymers with terminal double bonds by the reaction rates of all reactions taking place during polymerization.

$$
\begin{aligned}
\frac{\mathrm{d} Y_{0}}{\mathrm{~d} t}= & F_{i, S-1}^{Y_{0}}-F_{i, S}^{Y_{0}}+F_{i, S+1, r e c}^{Y_{0}}-F_{i, S, r e c}^{Y_{0}}+ \\
& 2 \cdot f \cdot k_{d} \cdot[I]-k_{t c} \cdot Y_{0}^{2}-k_{t d} \cdot Y_{0}^{2} \\
\frac{\mathrm{d} Y_{1}}{\mathrm{~d} t}= & F_{i, S-1}^{Y_{1}}-F_{i, S}^{Y_{1}}+F_{i, S+1, r e c}^{Y_{1}}-F_{i, S, r e c}^{Y_{1}}+ \\
& k_{p} \cdot[M] Y_{0}-k_{t c} \cdot Y_{0} \cdot Y_{1}-k_{t d} \cdot Y_{0} \cdot Y_{1}+ \\
& k_{f p} \cdot\left(Y_{0} \cdot Q_{2}-Y_{1} \cdot Q_{1}\right)+k_{f m} \cdot[M]\left(Y_{0}-Y_{1}\right)+ \\
& k_{d b} \cdot \alpha \cdot\left(Y_{0} \cdot Q_{2}-Y_{1} \cdot Q_{1}\right) \\
\frac{\mathrm{d} Y_{2}}{\mathrm{~d} t}= & F_{i, S-1}^{Y_{2}}-F_{i, S}^{Y_{2}}+F_{i, S+1, r e c}^{Y_{2}}-F_{i, S, r e c}^{Y_{2}}+ \\
& k_{p} \cdot[M]\left(2 \cdot Y_{1}+Y_{0}\right)-k_{t c} \cdot Y_{0} \cdot Y_{2}- \\
& k_{t d} \cdot Y_{0} \cdot Y_{2}+k_{f p} \cdot\left(Y_{0} \cdot Q_{3}-Y_{2} \cdot Q_{1}\right)+ \\
& k_{f m} \cdot[M]\left(Y_{0}-Y_{2}\right)+k_{d b} \cdot \alpha \cdot\left(Y_{0} \cdot Q_{3}-Y_{2} \cdot Q_{1}\right) \\
\frac{\mathrm{d} Q_{0}}{\mathrm{~d} t}= & F_{i, S-1}^{Q_{0}}-F_{i, S}^{Q_{0}}+F_{i, S+1, r e c}^{Q_{0}}-F_{i, S, r e c}^{Q_{0}}+ \\
& 0.5 \cdot k_{t c} \cdot Y_{0}^{2}+k_{t d} \cdot Y_{0}^{2}+ \\
& k_{f p} \cdot\left(-Y_{0} \cdot Q_{2}+Y_{1} \cdot Q_{1}\right)+ \\
& k_{f m} \cdot[M] Y_{0}-k_{d b} \cdot \alpha \cdot Q_{1} \cdot Y_{0} \\
\frac{\mathrm{d} Q_{1}}{\mathrm{~d} t}= & F_{i, S-1}^{Q_{1}}-F_{i, S}^{Q_{1}}+F_{i, S+1, r e c}^{Q_{1}}-F_{i, S, r e c}^{Q_{1}}+k_{t c} \cdot Y_{0} \cdot Y_{1}+ \\
& k_{t d} \cdot Y_{0} \cdot Y_{1}+k_{f p} \cdot\left(-Y_{0} \cdot Q_{2}+Y_{1} \cdot Q_{1}\right)+ \\
& k_{f m} \cdot[M] Y_{1}-k_{d b} \cdot \alpha \cdot Q_{2} \cdot Y_{0}
\end{aligned}
$$

$$
\begin{aligned}
\frac{\mathrm{d} Q_{2}}{\mathrm{~d} t}= & F_{i, S-1}^{Q_{2}}-F_{i, S}^{Q_{2}}+F_{i, S+1, r e c}^{Q_{2}}-F_{i, S, r e c}^{Q_{2}}+ \\
& k_{t c} \cdot\left(Y_{0} \cdot Y_{2}+Y_{1}^{2}\right)+k_{t d} \cdot Y_{0} \cdot Y_{2}+ \\
& k_{f p} \cdot\left(-Y_{0} \cdot Q_{3}+Y_{2} \cdot Q_{1}\right)+ \\
& k_{f m} \cdot[M] Y_{2}-k_{d b} \cdot \alpha \cdot Q_{3} \cdot Y_{0}
\end{aligned}
$$

where, $f$ is the initiator efficiency; $[I]$ is the initiator concentration $[\mathrm{mol} / \mathrm{l}] ; k_{d}$ is the decomposition rate constant of the initiator [1/s]; $k_{d b}$ is the reaction with terminal double bond rate constant $[1 / \mathrm{mol} \cdot \mathrm{s}]$; $k_{f m}$ is the transfer to monomer rate constant $[1 / \mathrm{mol} \cdot \mathrm{s}] ; k_{f p}$ is the transfer to polymer rate constant $[1 / \mathrm{mol} \cdot \mathrm{s}] ; k_{p}$ is the propagation rate constant $[1 / \mathrm{mol} \cdot \mathrm{s}] ; k_{t c}$ is the termination by combination rate constant $[1 / \mathrm{mol} \cdot \mathrm{s}] ; k_{t d}$ is the termination by disproportion rate constant $[1 / \mathrm{mol} \cdot \mathrm{s}] ;[M]$ is the monomer concentration $[\mathrm{mol} / \mathrm{l}] ; Y_{i}$ is the $i^{\text {th }}$ live polymer moment [mol/l]; $Q_{i}$ is the $i^{\text {th }}$ dead polymer moment $[\mathrm{mol} / \mathrm{l}] ; \alpha$ is the fraction of polymer with terminal double bounds.

The transfer to polymer reaction and reaction with terminal double bonds lead to polymer moment equations that are not closed, where the $i^{\text {th }}$ moment depends on the $(i+1)^{\text {th }}$ moment. To solve this problem, the closure technique presented by Hulburt and Katz [12] was used to calculate the third moment of the polymer distribution, as recommended by Zabisky et al. [11]. As such, the third moment of the dead polymer was calculated by Equation (13):

$Q_{3}=\left(\frac{Q_{2}}{Q_{1} \cdot Q_{0}}\right)\left(2 \cdot Q_{0} \cdot Q_{2}-Q_{1}^{2}\right)$

The kinetic parameters used in the simulations are presented in Table 1 and were based on the data published by Zabisky et al. [11] and Chan et al. [1]. The full dynamic mathematical model comprised 308 ordinary differential equations to calculate the

Table 1. Kinetic parameters for polyethylene homopolymer production $[1,11]$

\begin{tabular}{|l|c|c|}
\hline \multicolumn{1}{|c|}{ Reaction } & $\begin{array}{c}\mathbf{k}_{\mathbf{0}} \\
{[\mathbf{l} / \mathbf{m o l} \cdot \mathbf{s}]}\end{array}$ & $\begin{array}{c}\mathbf{E}_{\mathbf{a}} \\
{[\mathbf{c a l} / \mathbf{m o l}]}\end{array}$ \\
\hline Initiation $\left[\mathrm{s}^{-1}\right]$ & $8.4 \cdot 10^{15}$ & 36900 \\
\hline Propagation & $3.0 \cdot 10^{8}$ & 8065 \\
\hline Termination by disproportionation & $1.25 \cdot 10^{9}$ & 999 \\
\hline Termination by combination & $1.25 \cdot 10^{9}$ & 999 \\
\hline Transfer to monomer & $1.25 \cdot 10^{5}$ & 8078 \\
\hline Transfer to polymer & $2.0 \cdot 10^{8}$ & 21235 \\
\hline Reaction with terminal double bond & $1.25 \cdot 10^{7}$ & 8078 \\
\hline
\end{tabular}


material balance of all components, the energy balance and the population balance (via method of moments). The model was written in Fortran and was solved using a $5^{\text {th }}$ order Runge-Kutta integration method with variable integration step.

\section{Results and discussion}

Industrial production recipes from Politeno (Brazil) were used to simulate and validate the model. Validation of the model was carried out comparing the values predicted by the model with observed industrial steady-state values for monomer profile, initiator flow rates, temperature profile and final product characteristics.

The industrial reactor was divided into eight sections (Figure 1). The volumes of the reaction sections were $16.8,13.7,12.8,13.3,16.8,8.3,15.3$ and $3.0 \%$ of the total volume of the reactor. The monomer feed distribution assumed that 12.5, 25.0, 50.0 and $12.5 \%$ of the total monomer feed entered the first segment of sections $1,2,3$ and 5 respectively. The initiator (di-tert-butyl peroxide) was fed into the first segment of sections 2, 3, 4, 6 and 8 . The operating pressure was $1600 \mathrm{~atm}$ and the temperature of the ethylene feed was $353 \mathrm{~K}$. The temperature of the third segment of sections 2, 3, 4 and 6 and 8 were controlled at 513,513, 537, 513 and $531 \mathrm{~K}$, respectively.

The best controller parameters found for the reactor were: $K_{c}=0.0001, \tau_{D}=0.005, \tau_{I}=3.0$ for the first controlled section and $K_{c}=0.00005, \tau_{D}=0.005$,

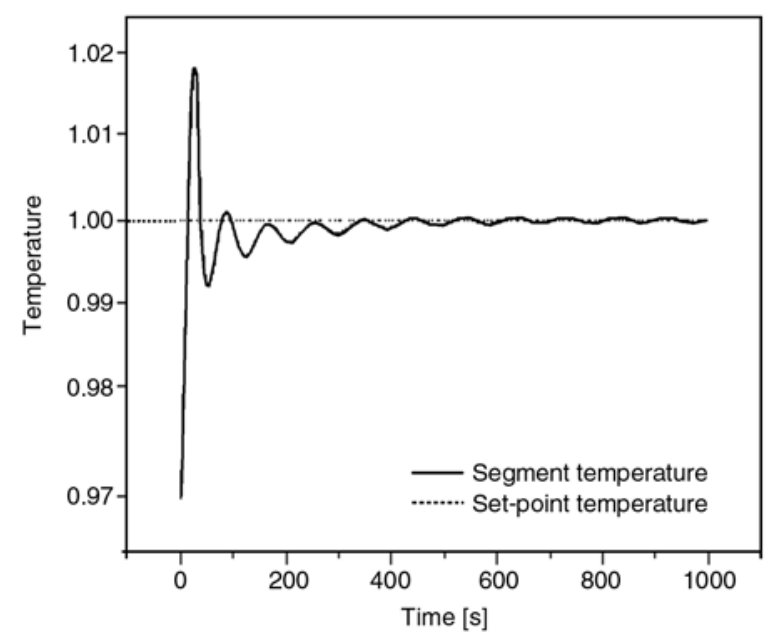

Figure 3. Dynamic response of an internal segment of the reactor (Segment 12). Temperature was normalized due to contract reasons
$\tau_{I}=5.0$ for the other controlled sections. Figure 3 shows a representative result of the variation of temperature (controlled variable) at reactor startup. Temperature control is a key factor for the operation of the autoclave reactor and it is very important that the controller manages to stabilize the temperature within a short time span. The PID controller implemented in the model and the control parameters found were able to control the temperature within a few residence times showing the efficiency of the control system.

The mixing parameters $(\theta$ and $\beta)$ are important parameters for the model and must be thoroughly studied, as well as the number of plug-flow segments within a section of the reactor $\left(N_{p}\right)$. Several simulations were carried out to find the best set of mixing parameters and $N_{p}$ for the industrial autoclave reactor being simulated.

These parameters need to be correctly estimated because they have a significant influence in the simulations and thus must be validated with industrial reactor data. The number of plug-flow segments was studied running simulations with 1 to 5 plug-flow segment in each section of the reactor. The addition of plug-flow segments in the model lead to a more gradual increase of segment temperature and a more gradual decrease of segment ethylene concentration. Figure 4 presents the effect of the number of plug-flow segments on temperature and ethylene concentration (for sections 2 and 3 ).

Although using a large number of plug-flow segments (7) have been suggested by Chan et al. [1], in our simulations we have observed that the use of only 2 plug-flow segments provided a more satisfactory simulation with the model with better representation of the industrial reactor. This result is corroborated by the observations made by Pladis and Kiparissides [10] for similar reactors. These results show that when the reactor has good backmixing of the reaction mixture the simulations should consider more plug-flow segments within each section because the changes in temperature and ethylene concentration along the reactor will be smoother. However, if the reactor does not present good back-mixing or if the flow rate of ethylene is high then the temperature along each reactor section will increase considerably. In this latter case, few plug-flow segments should be incorporated to the reactor model. 

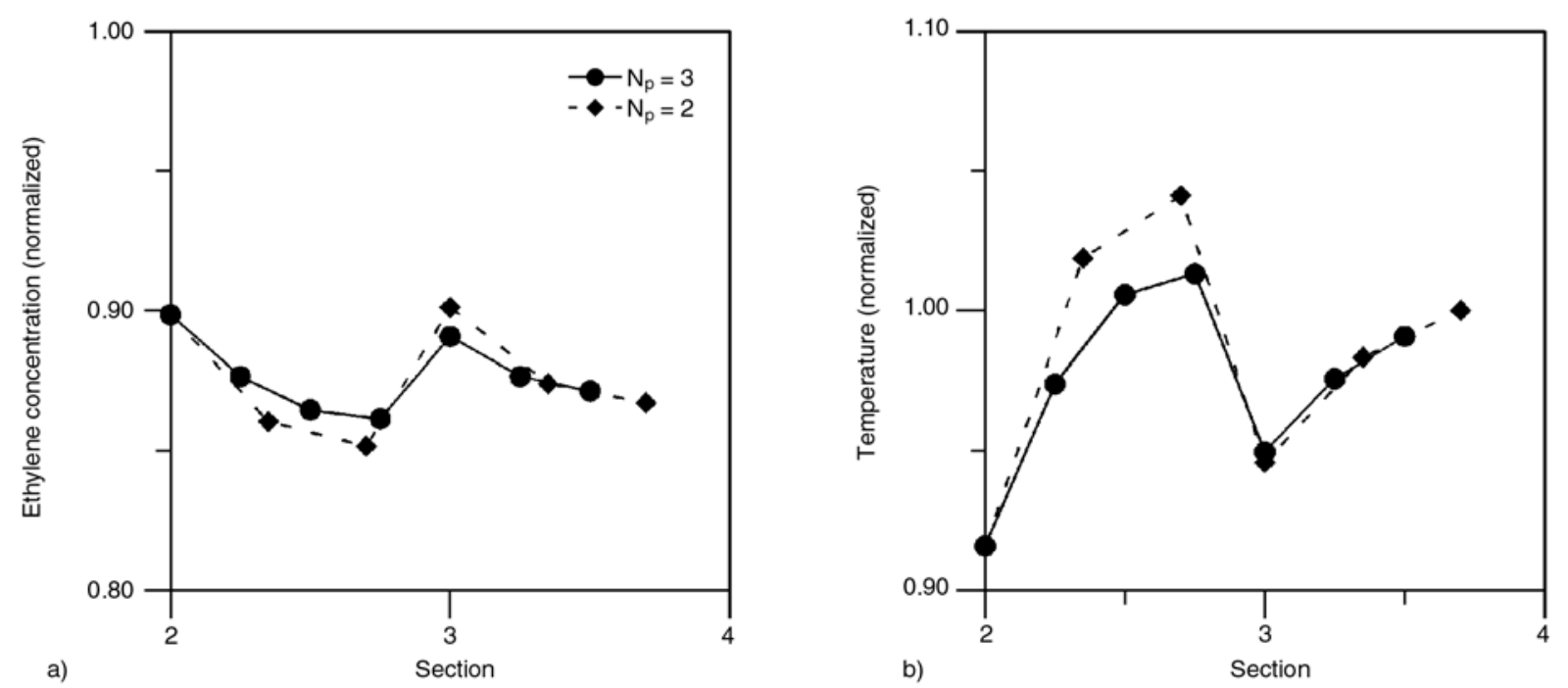

Figure 4. Effect of the number of plug-flow segments on monomer concentration (a) and temperature profiles (b) for sections 2 and 3 of the first reactor $(\theta=0.70)$

Volume fractions of the CSTR segment to the total volume of the section $(\theta)$ from 0.5 to 1.0 were studied. Increasing the CSTR segment volume $(\theta)$ in the model provided better mixing of the segment resulting in a gradual increase of temperature between the sections of the reactor, as well as a gradual decrease of ethylene concentration along the reactor. Figure 5 presents the effect of the CSTR segment volume on temperature and ethylene concentration (for sections 2 and 3 ).

Our simulations showed that the use of a CSTR segment volume of 0.70 provided a more satisfactory simulation with the model fitting better with the industrial reactor. This result corroborated with the observations made by Chan et al. [1] for a simi-

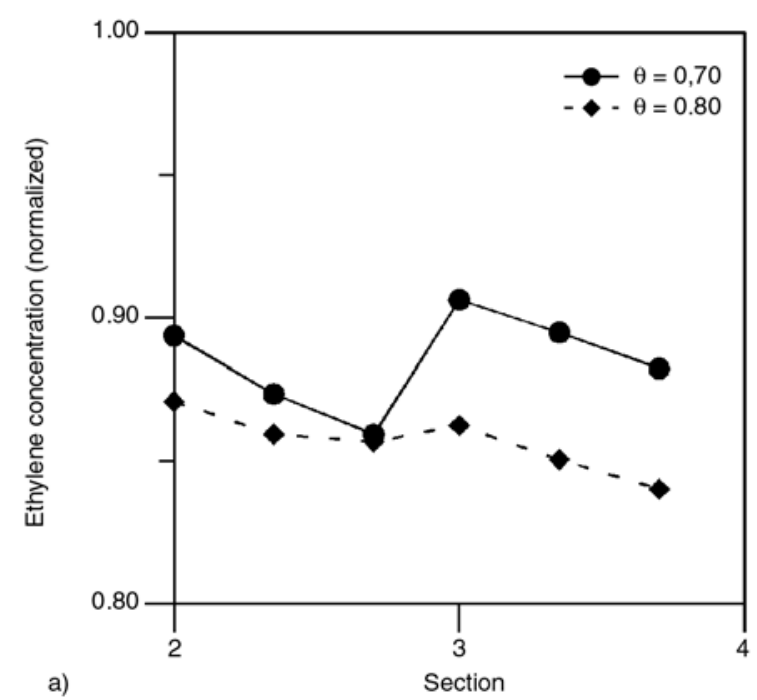

lar reactor. These results showed that the industrial reactor presents poor mixing in each segment and steep temperature and concentration variations occur near the feeding points of the reactor as is observed between sections 2 and 3 .

Recycle ratios $(\beta)$ from 0.0 to 0.4 were studied. The increase in the recycle ratio $(\beta)$ in the model provided better mixing among the sections resulting in a flatter temperature profile between the segments and the sections of the reactor. Figure 6 presents the effect of the CSTR segment volume on temperature and ethylene concentration for sections 2 and 3 . Figure 7 presents the same effect for all 8 sections of the two reactors.

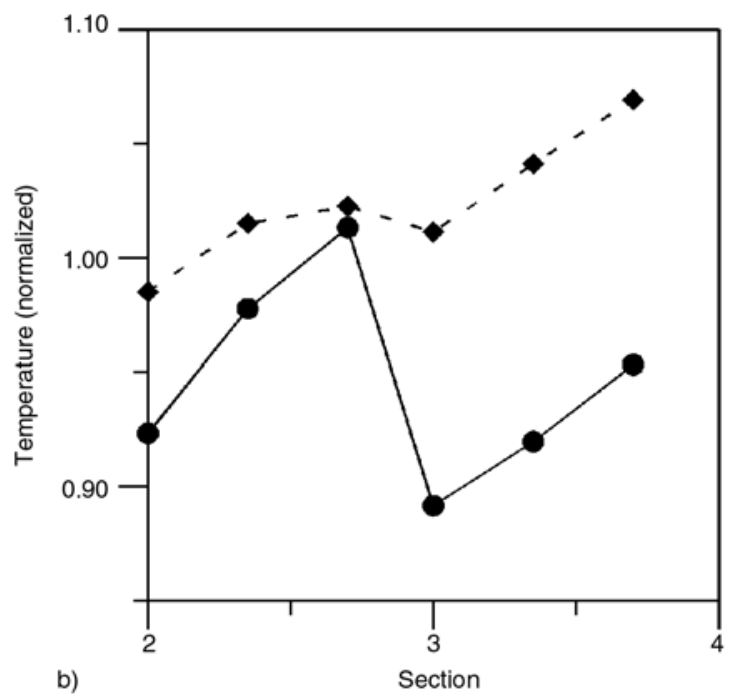

Figure 5. Effect of the CSTR segment volume on monomer concentration (a) and temperature profiles (b) for sections 2 and 3 of the first reactor $\left(N_{p}=2\right)$ 

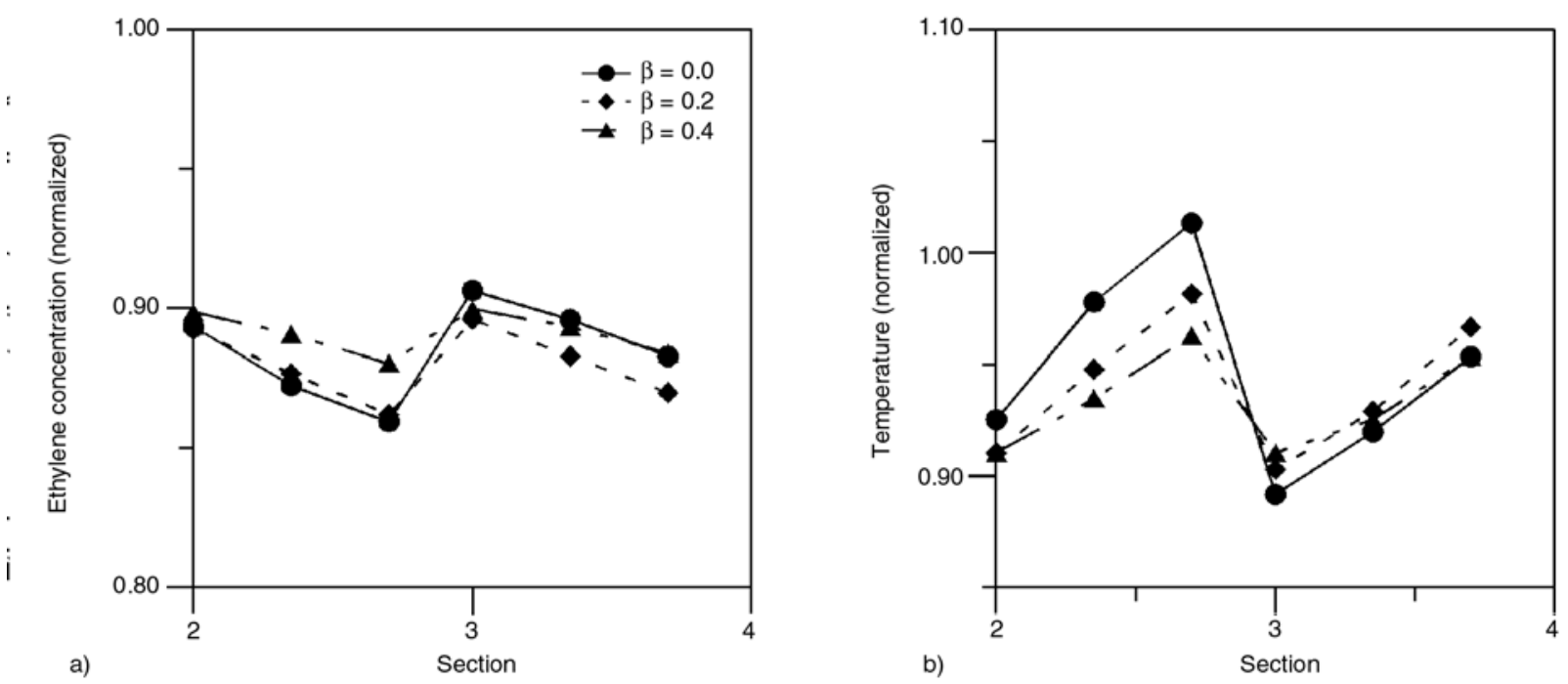

Figure 6. Effect of the recycle ratio on the monomer concentration (a) and the temperature profiles (b) for the first segment (CSTR segment) of each section of the reactor $\left(\theta=0.70 ; N_{p}=2\right)$
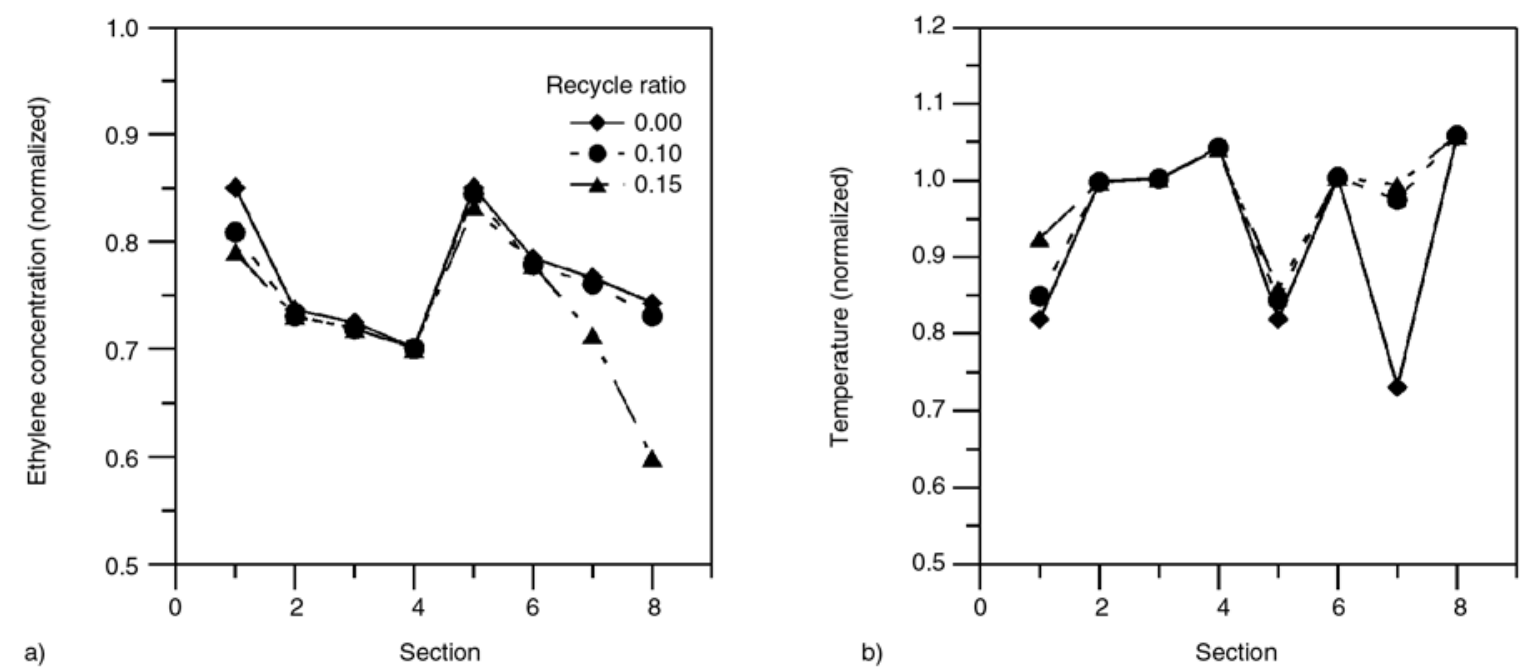

Figure 7. Effect of the recycle ratio on the monomer concentration (a) and the temperature profiles (b) for the first segment (CSTR segment) of each section of the reactor $\left(\theta=0.70 ; N_{p}=2\right)$

Comparing the profiles obtained in Figure 7 to actual reactor profiles have showed that none of the profiles obtained with simulations that were carried out with constant recycle ratios (all sections using the same recycle ratio) have displayed a satisfactory fit to the actual reactor data. Analyzing the configuration of the reactor and the fraction of ethylene feed in each section, we could establish that not all sections would display the same recycle ratio and that this parameter has to carefully set for each reactor design. For the design shown in Figure 1 , the recycle ratio of section 4 (towards section 3) was set to zero since the baffle between sections 3 and 4 minimizes the recycle and backmixing of the reaction mixture. The recycle ratio of section 3 (towards section 2) was increased since the flow rate of ethylene fed into section 3 is larger and as such a better mixing can occur near this feeding point. The best configuration found for the mixing parameters of the model where: volume fraction of the CSTR segment to the total volume of the section $(\beta)$ of 0.70 for all sections; and recycle ratio $(\beta)$ of $0.15,0.30,0.15,0.15$ and 0.05 for the sections 2, 3, 6, 7 and 8, respectively. A comparison with industrial data is shown in Figure 8.

The results found in Figure 8 are quite good and the largest relative error of the predicted values was less than $5 \%$ and as such we can state that the model truly represents the industrial reactor behavior. 


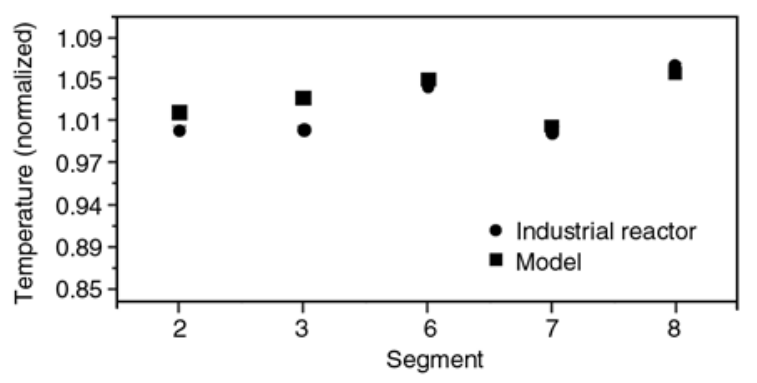

Figure 8. Comparison of temperature profiles between the proposed model and actual industrial data for polyethylene homopolymerization

\section{Conclusions}

A comprehensive model describing the high-pressure autoclave reactor for polyethylene production was developed, accounting for the mixing pattern in the reactor, the mechanistic polymerization reaction and temperature control. The model was proven satisfactory and has fitted homopolymer recipes for ethylene flow rates, initiator flow rates and temperature profiles.

\section{Acknowledgements}

The authors wish to acknowledge Politeno, Finep and $\mathrm{CNPq}$ for the financial support for this project.

\section{References}

[1] Chan W-M., Gloor P. E., Hamielec A. E.: Kinetic model for olefin polymerization in high-pressure autoclave reactors. AIChE Journal, 39, 111-126 (1993).

[2] Marini L., Georgakis C.: The effect of imperfect mixing on polymer quality in low density polyethylene vessel reactors. Chemical Engineering Communications, 30, 361-375 (1984).
[3] Marini L., Georgakis C.: Low density polyethylene vessel reactors. Part I: A novel controller. AIChE Journal, 30, 401-415 (1984).

[4] Topalis E., Pladis P., Kiparissides C., Goossens I.: Dynamic modelling and steady-state multiplicity in high pressure multizone LDPE autoclaves. Chemical Engineering Science, 51, 2461-2470 (1996).

[5] Sarmoria C., Brandolin A., López-Rodríguez A., Whiteley K. S., Del Amo Fernandez B.: Modeling of molecular weights in industrial autoclave reactors for high pressure polymerization of ethylene and ethylene-vinyl acetate. Polymer Engineering Science, 40, 1480-1494 (2000).

[6] Wells G. J., Ray W. H.: Mixing effects on performance and stability of low-density polyethylene reactors. AIChE Journal, 51, 3205-3218 (2005).

[7] Ghiass M., Hutchinson R. A.: Simulation of free radical high-pressure copolymerization in a multi-zone autoclave reactor: Compartment model investigation. Macromolecular Symposia, 206, 443-456 (2004).

[8] Ghiass M., Hutchinson R. A.: Simulation of free radical high-pressure copolymerization in a multi-zone autoclave reactor: Model development and application. Polymer Reaction Engineering, 11, 989-1015 (2004).

[9] López A., Pedraza J. J., Del Amo B.: Industrial application of a simulation model for high pressure polymerization of ethylene. Computers and Chemical Engineering, 20, S1625-S1630 (1996).

[10] Pladis P., Kiparissides C.: Dynamic modeling of multizone, multifeed high-pressure LDPE autoclaves. Journal of Applied Polymer Science, 73, 2327-2348 (1999).

[11] Zabisky R. C. M., Chan W-M., Gloor P. E., Hamielec A. E.: A kinetic model for olefin polymerization in high-pressure tubular reactors: a review and update. Polymer, 33, 2243-2262 (1992).

[12] Hulburt H. M., Katz S.: Some problems in particle technology: A statistical mechanical formulation. Chemical Engineering Science, 19, 555-574 (1964). 